\title{
IMPLEMENTASI TEMPLATE WEB RESPONSIVE DYNAMIS (STUDI KASUS: WEBSITE LEMBAGA PENJAMINAN MUTU DAN PENGEMBANGAN PENDIDIKAN)
}

\author{
Gunawan $^{1}$, Sandhy Fernandes ${ }^{2}$ \\ ${ }^{1,2}$ Universitas Muhammadiyah Bengkulu \\ Jln. Bali Kota Bengkulu \\ Email: gunawan@umb.ac.id ${ }^{1}$, sandhyfernandes@umb.ac.id ${ }^{2}$
}

\begin{abstract}
LPMPP function as an institution that is fully responsible for the implementation of quality assurance mechanisms that have been established based PPEPP Internal Quality Assurance System (SPMI) as determined by UM Bengkulu. In fact, LPMPP has yet to have an information system website that provides all the information needed for applications for re-accreditation of tertiary institutions and study programs. The provision of the website is expected to provide information about the activities that have been implemented by LPMPP with responsive displays that adapts to the screen size of the mobile phone. Website supported by the dynamic capabilities that can provide system data information is up to date.
\end{abstract}

Keyword : Dynamist, LPMPP, Responsive, Website

\section{PENDAHULUAN}

Universitas Muhammadiyah Bengkulu (UM Bengkulu) memiliki Lembaga Penjaminan Mutu yang dibentuk berdasarkan Surat Keputusan Rektor yang diterbitkan pada tahun 2018 yaitu Lembaga Penjaminan Mutu dan Pengembangan Pendidikan (LPMPP). LPMPP berfungsi sebagai Lembaga yang bertanggung jawab penuh atas terlaksananya mekanisme penjaminan mutu PPEPP yang telah ditetapkan berdasarkan Sistem Penjaminan Mutu Internal (SPMI) yang telah ditetapkan oleh UM Bengkulu. Pada kenyataannya LPMPP sampai saat ini belum meliliki website sistem informasi yang menyajikan seluruh informasi yang dibutuhkan untuk keperluan pengajuan re-akreditasi perguruan tinggi maupun program studi. Penyedian website diharapkan mampu memberikan informasi kegiatan-kegiatan yang telah dilaksanakan oleh LPMPP.

Menurut (Anugerah 2013) Kebutuhan akan perangkat lunak untuk mendorong produktifitas, makin hari makin dirasa bertambah seiring dengan perkembangan teknologi. Salah satu perkembangan teknologi yang ikut memicu kebutuhan akan perangkat lunak, untuk mendorong produktifitas suatu lembaga 
adalah website. Namun, untuk membuat website memerlukan keahlian dan keterampilan, selain cermat dan berpikir ke depan untuk mengisi konten. Konten yang didistribusikan melalui website pun harus bisa responsive pada perangkat pengguna yang sangat beragam.

Namun kenyataan yang tak bisa dipungkiri bahwa semakin hari penggunaan smartphone semakin besar dan semakin menjadi kebutuhan masyarakat banyak dalam melakukan komunikasi. Menurut situs www.mobithinking.com, pada tahun 2012, penggunaan mobile phone telah melampui penggunana fixed telephone sebanyak 6:1 dan Indonesia merupakan negara ke-4 terbesar pengguna mobile phone yaitu 260 juta sim card atau 107,3\% dari jumlah populasi penduduk Indonesia. Naiknya penggunaan mobile telephone ini, otomatis membuat naiknya akses ke Internet dari mobile phone, khususnya lagi smartphone. Menurut situs www.cisco.com, penggunaan smartphone untuk mengakses Internet telah naik 81\% pada tahun 2012, dan pada tahun 2012 saja traffic ke Internet dari mobile phone ini sudah 12 kali lebih besar dari seluruh traffic Internet pada tahun 2000. Di banyak negara (China dan Korea sebagai contoh) akses Internet menggunakan mobile phone sudah mengalahkan akses Internet lewat PC, banyak ahli sudah memperkirakan bahwa pada tahun 2014 akses Internet melalui Smartphone dan Tablet akan lebih besar jumlahnya daripada akses Internet melalui PC dan Laptop. Menurut (Alatas 2013) Meningkatnya akses Internet dari mobile phone dan tablet ini, menimbulkan budaya baru dan juga kebutuhan baru, antara lain adalah tersedianya website yang tetap tampil elegan walau dibuka dengan mobile phone tersebut. Atau dengan perkataan lain, tersedianya website yang responsive terhadap ukuran layar mobile phone, bahkan Google sendiri menyatakan bahwa Responsive Web merupakan cara terbaik untuk membuat website bagi mobile device.

Penelitian ini diharapkan mampu menghasilkan informasi berupa website responsive yang mampu menyedikan seluruh data yang dibutuhkan oleh perguruan tinggi dan program studi. Sehingga efesiensi dan kepraktisan data dapat diakses malalui website yang akan dihasilkan.

Menurut (Wijaya and Gunawan 2018) Dalam Kamus Besar Bahasa Indonesia, implementasi adalah pelaksanaan dan penerapan, dimana kedua hal ini 
bermaksud untuk mencari bentuk tentang hal yang disepakati terlebih dahulu. Implementasi adalah proses untuk memastikan terlaksananya suatu kebijakan dan tercapainya kebijakan tersebut. Tujuan dari implementasi sebuah sistem ialah untuk menyelesaikan desain system yang telah disetujui, menguji serta mendokumentasikan program-program dan prosedur sistem yang diperlukan, memastikan bahwa personil yang terlibat dapat mengoperasikan sistem yang baru dan memastikan bahwa konversi sistem lama ke sistem baru dapat berjalan dengan baik dan benar. Menurut (Irawan and Simargolang 2018) Implementasi merupakan suatu proses mendapatkan suatu hasil yang sesuai dengan tujuan atau sasaran kebijakan itu sendiri. Dimana pelaksana kebijakan melakukan suatu aktivitas atau kegiatan. Menurut (Haryati, Sudarsono, and Suryana 2015) Implementasi adalah perluasan aktivitas yang saling menyesuaikan. Pengertian implementasi sebagai aktivitas yang saling menyesuaikan. Setelah sistem informasi yang baru dirancang, sistem tersebut harus diimplementasikan sebagai sistem kerja, dan dipelihara agar dapat berrjalan dengan baik. Proses implementasi yang akan kita bahas dalam bagian ini adalah kelanjutan dari tahap investigasi, analis, dan desain siklus pengembangan sistem yang kita bahas. Implementasi adalah langkah yang vital dalam pengembangan teknologi informasi untuk mendukung karyawan, pelanggan, dan pihak pihak yang berkepentingan lainnya.

Menurut (Heny 2016) Website adalah sebuah cara untuk menampilkan diri di Internet. Dapat diibaratkan :HEVLWH adalah sebuah tempat di Internet, siapa saja di dunia ini dapat mengunjunginya, kapan saja seseorang dapat mengetahui tentang diri orang lain, memberi pertanyaan pada seseorang, serta memberikan masukkan atau bahkan mengetahui dan membeli suatu produk. Menurut (Nandari and Sukadi 2014) Web Server adalah tempat anda mendapatkan halaman web dan data yang berhubungan dengan website yang anda buat, sehingga data dapat diakses dan dilihat oleh orang lain.

Menurut (Budiyono 2016) Template adalah model atau prototype web atau halaman web yang setiap detailnya identik dengan web atau halaman web yang sebenarnya. Menurut (Bettaliyah 2016)Web Mobile atau Responsive Web Design sendiri adalah sebuah teknik yang digunakan untuk membuat layout website menyesuaikan diri dengan tampilan device pengunjung, baik ukuran maupun 
orientasinya. Jadi tampilan yang berada di desktop komputer dengan tampilan yang diakses melalu Smart Phone misalnya, itu akan berbeda tampilannya. Codeigniter adalah sebuah framework PHP yang dapat membantu mempercepat developer dalam pengembangan aplikasi web berbasis $P H P$ dibandingkan jika menulis semua kode program dari awal. Codeigniter menyediakan banyak library untuk mengerjakan tugas -tugas yang umumnya ada pada sebuah aplikasi berbasis web.

Menurut (Budiyono 2016) Situs web dinamis merupakan situs web yang secara spesifik didisain agar isi yang terdapat dalam situs tersebut dapat diperbarui secara berkala dengan mudah. Sesuai dengan namanya, isi yang terkadung dalam situs web ini umumnya akan berubah setelah melewati satu periode tertentu. Situs berita adalah salah satu contoh jenis situs yang umumnya mengimplementasikan situs web dinamis. Tidak seperti halnya situs web statis, pengimplementasian situs web dinamis umumnya membutuhkan keberadaan infrastruktur yang lebih kompleks dibandingkan situs web statis. Hal ini disebabkan karena pada situs web dinamis halaman web umumnya baru akan dibuat saat ada pengguna yang mengaksesnya, berbeda dengan situs web statis yang umumnya telah membentuk sejumlah halaman web saat diunggah di server web sehingga saat pengguna mengaksesnya server web hanya tinggal memberikan halaman tersebut tanpa perlu membuatnya terlebih dulu.

\section{METODE PENELITIAN}

Proses yang digunakan dalam membuat Website Dynamis LPMPP Responsive:

1. Pengumpulan kebutuhan

Mendefinisikan format dan kebutuhan keseluruhan perangkat lunak, mengidentifikasikan semua kebutuhan, dan garis besar sistem yang akan dibuat.

2. Membangun prototyping

Membangun prototyping dengan membuat perancangan sementara yang berpusat pada penyajian (misalnya dengan membuat input dan contoh outputnya). 
3. Evaluasi prototyping

Evaluasi ini dilakukan apakah prototyping yang sudah dibangun sudah sesuai dengan keinginan Jika sudah sesuai maka langkah keempat akan diambil. Jika tidak, maka prototyping diperbaiki dengan mengulang langkah 1, 2 ,3.

4. Mengkodekan system

Dalam tahap ini prototyping yang sudah disepakati diterjemahkan ke dalam bahasa pemrograman yang sesuai.

5. Menguji system

Setelah sistem sudah menjadi suatu perangkat lunak yang siap pakai, harus dites dahulu sebelum digunakan. Pengujian ini dilakukan dengan Pengujian Beta.

6. Evaluasi Sistem

Mengevaluasi apakah sistem yang sudah jadi sudah sesuai dengan yang diharapkan. Jika sudah, maka langkah ketujuh dilakukan, jika belum maka mengulangi langkah 4 dan 5 .

7. Menggunakan system

Perangkat lunak yang telah diuji siap untuk digunakan. 


\section{HASIL DAN PEMBAHASAN}

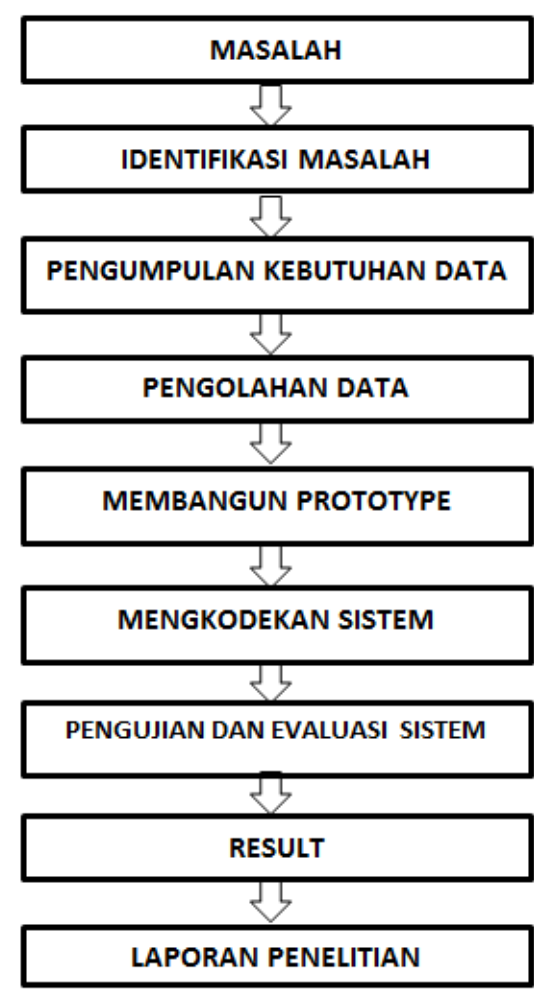

Gambar 1. Kerangka Kerja Sumber : (Wijaya and Gunawan 2018)

1. Langkah Indentifikasi masalah

a. Masalah

Permasalahan yang dihadapi peneliti pada penelitian ini adalah, belum adanya website LPMPP Universitas Muhammadiyah Bengkulu.

b. Identifikasi Masalah

Dilakukan untuk mengetahui bagaimana pembuatan Website LPMPP yang diimplementasikan denga template responsive dynamis.

2. Pengumpulan Data

Tahapan ini dilakukan untuk melengkapi proses analisis dan identifikasi masalah yang ada agar penelitian yang dilakukan lebih terarah dengan baik.

a. Studi Pustaka

Proses ini dilakukan dengan mengumpulkan sejumlah literature awal, berupa jurnal-jurnal penelitian serta buku-buku terkait agar lebih memperdalam peneliti dalam menemukan informasi dan ide. 


\section{b. Observasi}

Langkah ini dilakukan secara langsung dengan meninjau dan menanyakan secara langsung permintaan informasi apa saja yang biasanya dibutuhkan oleh user dalam pencarian informasi di LPMPP.

c. Wawancara

Langkah ini dilakukan untuk mendapat gambaran lebih terhadap website lain yang sudah ada kepada UPT TIK, sehingga peneliti dapat mengumpulkan informasi lebih dan memudah kan dalam proses perancangan kedepannya.

\section{Pengolahan Data}

Setelah teknik pengumpulan data dilakukan, selanjutnya adalah melakuka n pengolahan data, pentingnya pengolahan data diantaranya adalah: Data yang telah terkumpul perlu diolah dahulu, tujuannya menyederhanakan seluruh data yang terkumpul, menyajikannya dalam susunan yang baik dan rapi, kemudian dianalisis.

4. Membangun Prototype

Membangun prototyping dengan membuat perancangan sementara yang bepusat pada penyajian (misalnya membuat input dan contoh outputnya).

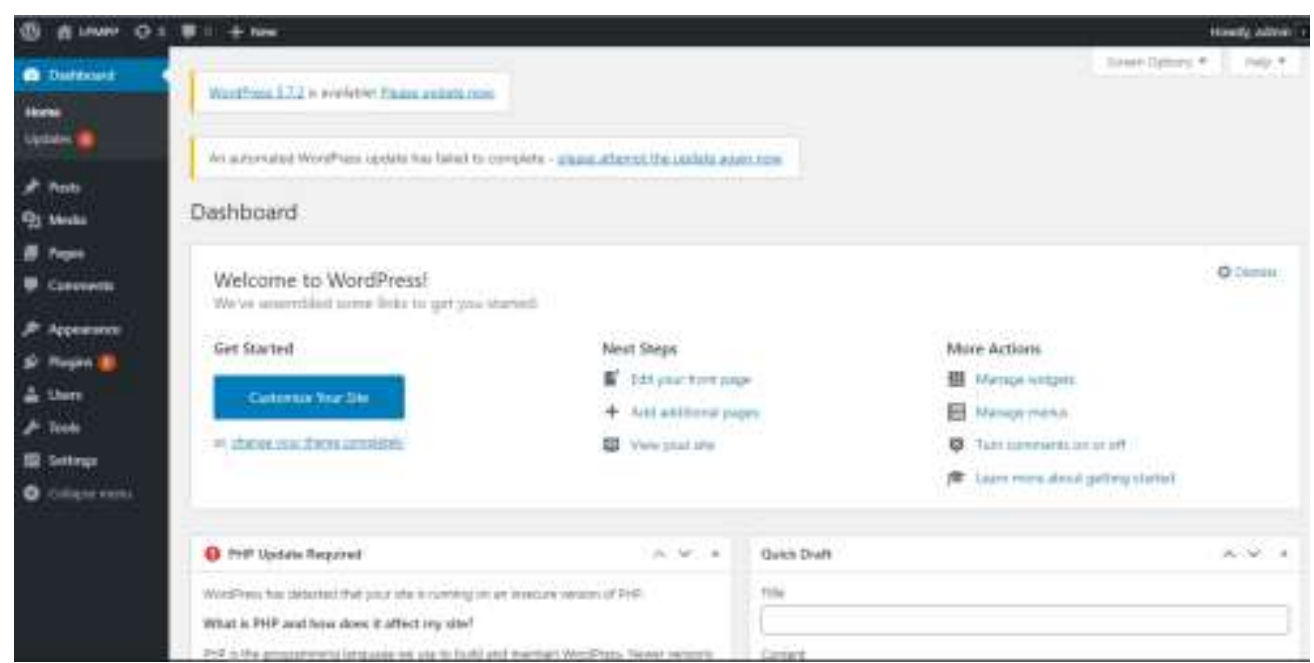

Gambar 2. Tampilan Login admin Worpress (Input) 


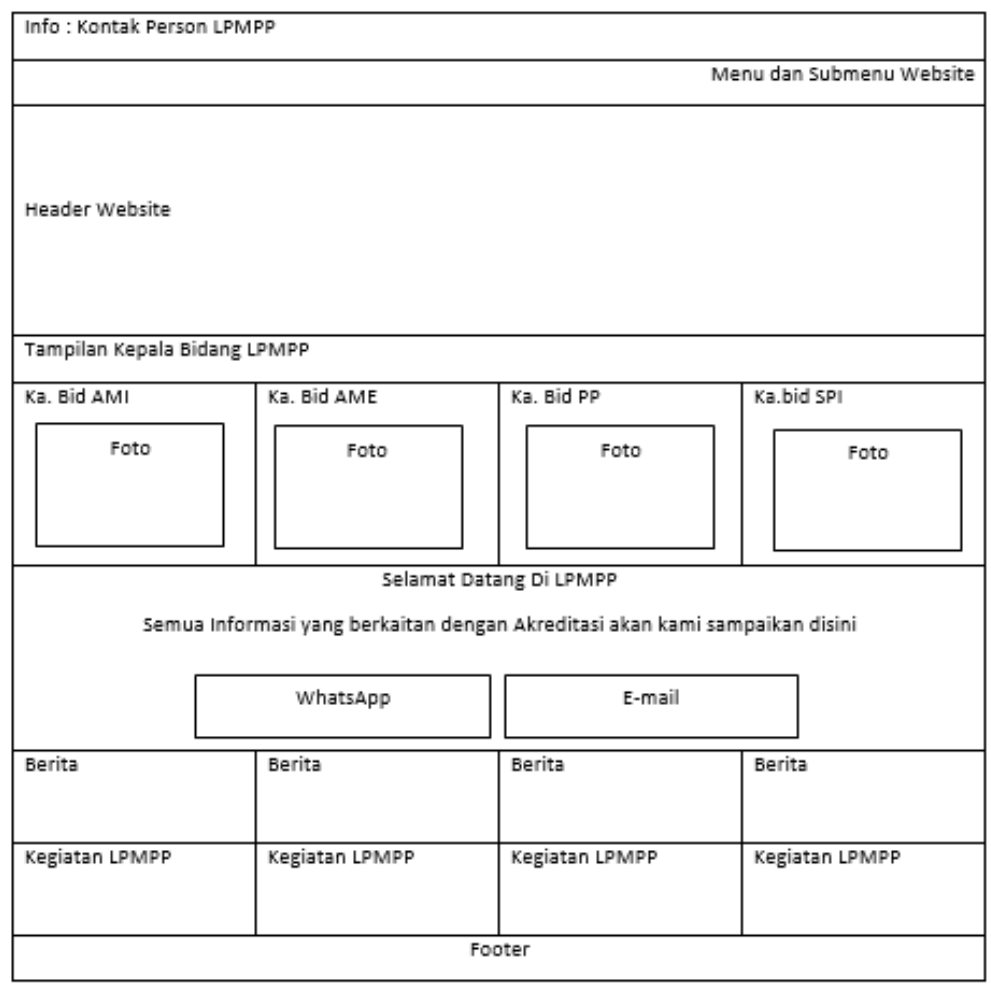

Gambar 3. Rancangan Tampilan web (Output)

\section{Mengkodekan Sistem}

Langkah ini dilakukan setelah proses pembuatan rancangan website sistem informasi lalu implementasikan menggunakan template website wordpress yang telah mendukung responsive dan dynamis dengan template wordpress yang berbayar. Langkah mengkodekan sistem ini menggunakan costomize tampilan worpress dengan menambahkan beberapa plugin, template wordpess yang digunakan adalah education soul

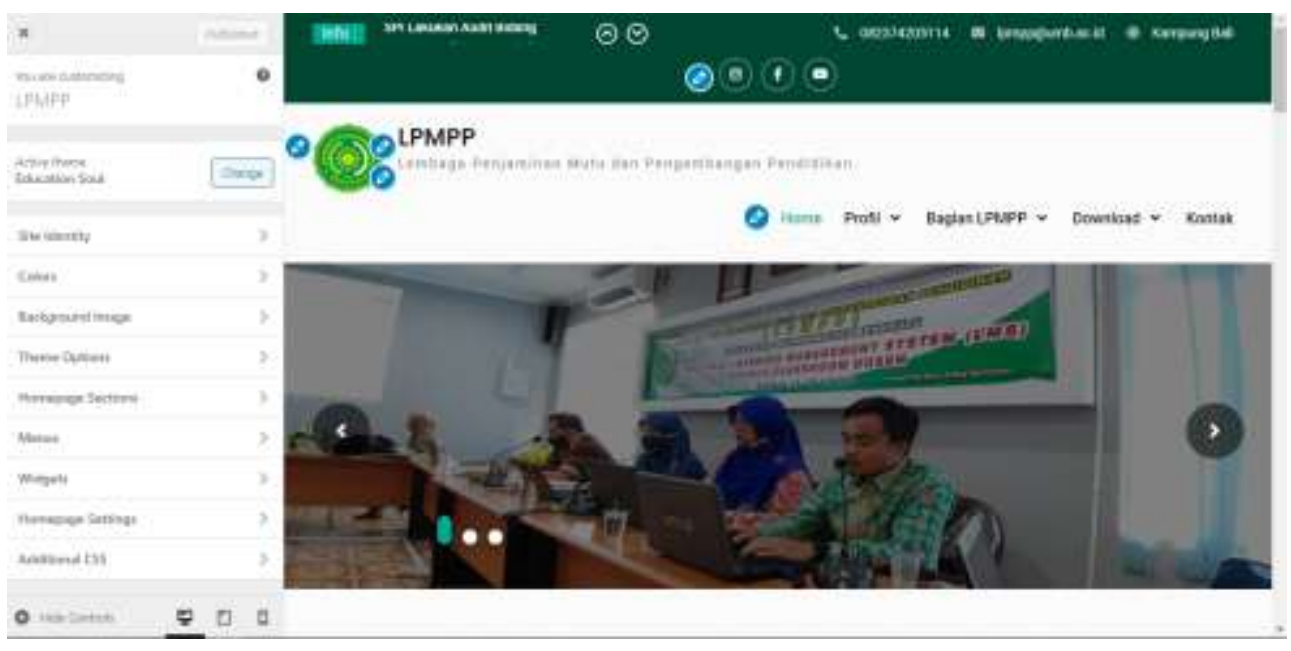

Gambar 4. Pengkodean (customize) 
6. Pengujian dan Evaluasi Sistem

Pada system aplikasi ini dilakukan pengujian Beta. Pengujian Beta merupakan pengujian yang dilakukan oleh beberapa pengguna website. Hal ini dilakukan untuk mengetahui apakah sudah sesuai dengan seperti yang penulis harapkan. Dalam pengujian beta penulis menggunakan 15 pertanyaan dengan menyebarkan kousiner melaluai google forms dengan melampirkan alamat link website http://lpmpp.umb.ac.id/, kuisioner dengan skala 1-4.

Tabel 1 Skala Pengujian Beta

\begin{tabular}{|cc|}
\hline Tingkat Kepuasan & Skala \\
\hline Sangat Setuju (SS) & 4 \\
\hline Setuju (S) & 3 \\
\hline Tidak Setuju (TS) & 2 \\
\hline Sangat Tidak Setuju (STS) & 1 \\
\hline
\end{tabular}

Sumber : (Suandi, Khasanah, and Retnoningsih 2017)

Berdasarkan data hasil kuesioner, didapat persentase masing-masing jawaban dengan menggunakan rumus :

$$
Y=\frac{\Sigma(\mathrm{N} \cdot \mathrm{R})}{\text { Skor Ideal }} \times 100 \%
$$

Keterangan :

$\mathrm{Y}=$ Nilai persentase yang dicari

$\mathrm{X}=$ Jumlah nilai kategori jawaban dikalikan dengan frekuensi $(\Sigma=$ N.R $)$

$\mathrm{N}=$ Nilai dari setiap jawaban

$\mathrm{R}=$ Frekuensi

Skor ideal $=$ Nilai tertinggi dikalikan dengan jumlah sampel $(4$ X $5=20)$

Tabel 2. Hasil Pengujian Beta

\begin{tabular}{|c|c|c|c|c|c|c|c|}
\hline Pertanyaan & $\begin{array}{c}\text { Jawaban } \\
\text { Responden }\end{array}$ & $(\mathrm{N})$ & $(\mathrm{R})$ & (N.R) & $\sum_{(\mathrm{N} . \mathrm{R})}$ & $(\mathrm{Y})$ & Hasil \\
\hline \multirow{4}{*}{$\begin{array}{l}\text { Web ini mudah untuk } \\
\text { dioperasikan atau } \\
\text { digunakan (User } \\
\text { friendly) }\end{array}$} & SS & 4 & 4 & 16 & \multirow{4}{*}{19} & \multirow{4}{*}{$95 \%$} & \multirow{4}{*}{$\begin{array}{l}\text { Website LPMPP } \\
\text { mudah } \\
\text { digunakan (User } \\
\text { friendly) }\end{array}$} \\
\hline & $\mathrm{S}$ & 3 & 1 & 3 & & & \\
\hline & TS & 2 & 0 & 0 & & & \\
\hline & STS & 1 & 0 & 0 & & & \\
\hline \multirow{4}{*}{ dan da } & SS & 4 & 1 & 4 & \multirow{4}{*}{16} & \multirow{4}{*}{$80 \%$} & \multirow{4}{*}{$\begin{array}{l}\text { Interaksi Jelas } \\
\text { dan mudah } \\
\text { dimengerti }\end{array}$} \\
\hline & $\mathrm{S}$ & 3 & 4 & 12 & & & \\
\hline & $\mathrm{TS}$ & 2 & 0 & 0 & & & \\
\hline & STS & 1 & 0 & 0 & & & \\
\hline \multirow{4}{*}{$\begin{array}{l}\text { 3. Website LPMPP } \\
\text { tampilannya menarik }\end{array}$} & SS & 4 & 4 & 16 & \multirow{4}{*}{19} & \multirow{4}{*}{$95 \%$} & \multirow{4}{*}{$\begin{array}{l}\text { Tanpilan } \\
\text { Website LPMPP } \\
\text { menarik }\end{array}$} \\
\hline & $S$ & 3 & 1 & 3 & & & \\
\hline & TS & 2 & 0 & 0 & & & \\
\hline & STS & 1 & 0 & 0 & & & \\
\hline
\end{tabular}




\begin{tabular}{|c|c|c|c|c|c|c|c|c|}
\hline \multirow{4}{*}{\multicolumn{2}{|c|}{$\begin{array}{l}\text { 4. Tata letak tampilan } \\
\text { dalam website } \\
\text { LPMPP tepat }\end{array}$}} & SS & 4 & 4 & 16 & \multirow{4}{*}{19} & \multirow{4}{*}{$95 \%$} & \multirow{4}{*}{$\begin{array}{l}\text { Tata letak } \\
\text { tampilan tepat }\end{array}$} \\
\hline & & $\mathrm{S}$ & 3 & 1 & 3 & & & \\
\hline & & TS & 2 & 0 & 0 & & & \\
\hline & & STS & 1 & 0 & 0 & & & \\
\hline \multirow[t]{4}{*}{5.} & Alamat Website & SS & 4 & 4 & 16 & \multirow{4}{*}{19} & \multirow{4}{*}{$95 \%$} & \multirow{4}{*}{$\begin{array}{l}\text { Website LPMPP } \\
\text { mudah diakases }\end{array}$} \\
\hline & LPMPP mudah & S & 3 & 1 & 3 & & & \\
\hline & diakses & $\mathrm{TS}$ & 2 & 0 & 0 & & & \\
\hline & & STS & 1 & 0 & 0 & & & \\
\hline \multirow[t]{4}{*}{6.} & Website LPMPP & SS & 4 & 4 & 16 & \multirow{4}{*}{19} & \multirow{4}{*}{$95 \%$} & \multirow{4}{*}{$\begin{array}{l}\text { Tampilan } \\
\text { Website LPMPP } \\
\text { responsive }\end{array}$} \\
\hline & menyusuaikan & $S$ & 3 & 1 & 3 & & & \\
\hline & tampilkan ketika di & TS & 2 & 0 & 0 & & & \\
\hline & akses & STS & 1 & 0 & 0 & & & \\
\hline \multirow[t]{4}{*}{7.} & user dapat mencari & SS & 4 & 1 & 4 & \multirow{4}{*}{14} & \multirow{4}{*}{$70 \%$} & \multirow{4}{*}{$\begin{array}{l}\text { Informasi } \\
\text { mudah dicari }\end{array}$} \\
\hline & informasi LPMPP & $\mathrm{S}$ & 3 & 3 & 9 & & & \\
\hline & & $\mathrm{TS}$ & 2 & 0 & 0 & & & \\
\hline & & STS & 1 & 1 & 1 & & & \\
\hline & Informasi yang & SS & 4 & 1 & 4 & \multirow{4}{*}{14} & \multirow{4}{*}{$70 \%$} & \multirow{4}{*}{$\begin{array}{l}\text { Informasi } \\
\text { memnuhi } \\
\text { kebutuhan }\end{array}$} \\
\hline & ditampilkan & $\mathrm{S}$ & 3 & 3 & 9 & & & \\
\hline & memenuhi & $\mathrm{TS}$ & 2 & 0 & 0 & & & \\
\hline & kebutuhan user & STS & 1 & 1 & 1 & & & \\
\hline \multirow[t]{4}{*}{9.} & Teks yang & SS & 4 & 4 & 16 & & & Teks Tampilan \\
\hline & ditampilkan Dapat & $\mathrm{S}$ & 3 & 1 & 3 & & $05 \%$ & terbaca dengan \\
\hline & dibaca dengan jelas & TS & 2 & 0 & 0 & 19 & $95 \%$ & \\
\hline & & STS & 1 & 0 & 0 & & & \\
\hline 10 & . Menu-menu & SS & 4 & 4 & 16 & & & Fungi menu \\
\hline & berfungsi dengan & $\mathrm{S}$ & 3 & 1 & 3 & 10 & $05 \%$ & baik \\
\hline & baik & TS & 2 & 0 & 0 & 19 & $95 \%$ & \\
\hline & & STS & 1 & 0 & 0 & & & \\
\hline & 1. Terjadi gangguan & $\mathrm{SS}$ & 4 & 0 & 0 & & & Tidak Terjadi \\
\hline & Ketika mengunduh & $\mathrm{S}$ & 3 & 0 & 0 & & & gangguan saat \\
\hline & sesuai melalui & TS & 2 & 1 & 4 & 16 & $80 \%$ & mengunduh \\
\hline & website & STS & 1 & 4 & 12 & & & \\
\hline & 2. User dapat & SS & 4 & 4 & 16 & & & Interaksi Fast \\
\hline & berinteraksi dengan & $S$ & 3 & 1 & 3 & 10 & $05 \%$ & Respon \\
\hline & kontak person WA & $\mathrm{TS}$ & 2 & 0 & 0 & 19 & $95 \%$ & \\
\hline & & STS & 1 & 0 & 0 & & & \\
\hline & 3. Informasi yang & SS & 4 & 4 & 16 & & & Informasi yang \\
\hline & disajikan up to date & $S$ & 3 & 1 & 3 & 10 & $05 \%$ & ditampilkan up \\
\hline & & TS & 2 & 0 & 0 & 19 & $95 \%$ & to date \\
\hline & & STS & 1 & 0 & 0 & & & \\
\hline & 4. Kegiatan yang & SS & 4 & 3 & 12 & & & Kegiatan \\
\hline & ditampilkan lengkap & $\mathrm{S}$ & 3 & 2 & 6 & 18 & $00 \%$ & LPMPP lengkap \\
\hline & & $\mathrm{TS}$ & 2 & 0 & 0 & 18 & $90 \%$ & \\
\hline & & STS & 1 & 0 & 0 & & & \\
\hline 15 & 5. Foto kegiatan bisa & SS & 4 & 3 & 12 & & & Foto Kegiatan \\
\hline & disimpan & $\mathrm{S}$ & 3 & 2 & 6 & 18 & $00 \%$ & bisa disimpan \\
\hline & & TS & 2 & 0 & 0 & 18 & $90 \%$ & \\
\hline & & STS & 1 & 0 & 0 & & & \\
\hline
\end{tabular}




\section{Result}

Hasil yang diharapkan pada penelitian ini adalah system ataupun perangkat lunak yang dihasilkan dapat berjalan sebagaimana mestinya. Berjalan dengan efektif dan efisien.

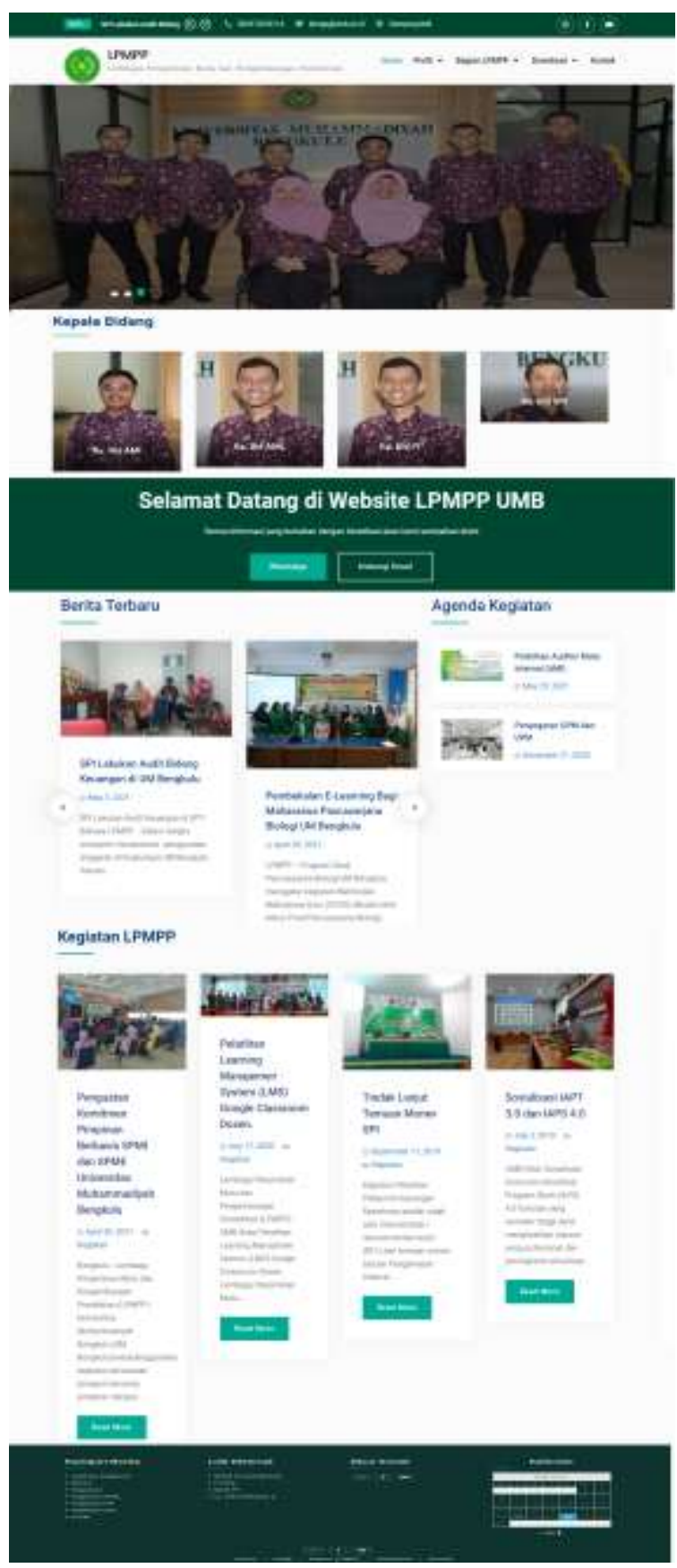

Gambar 5. Tampilan Keseluruhan Website (akses PC/Laptop) 


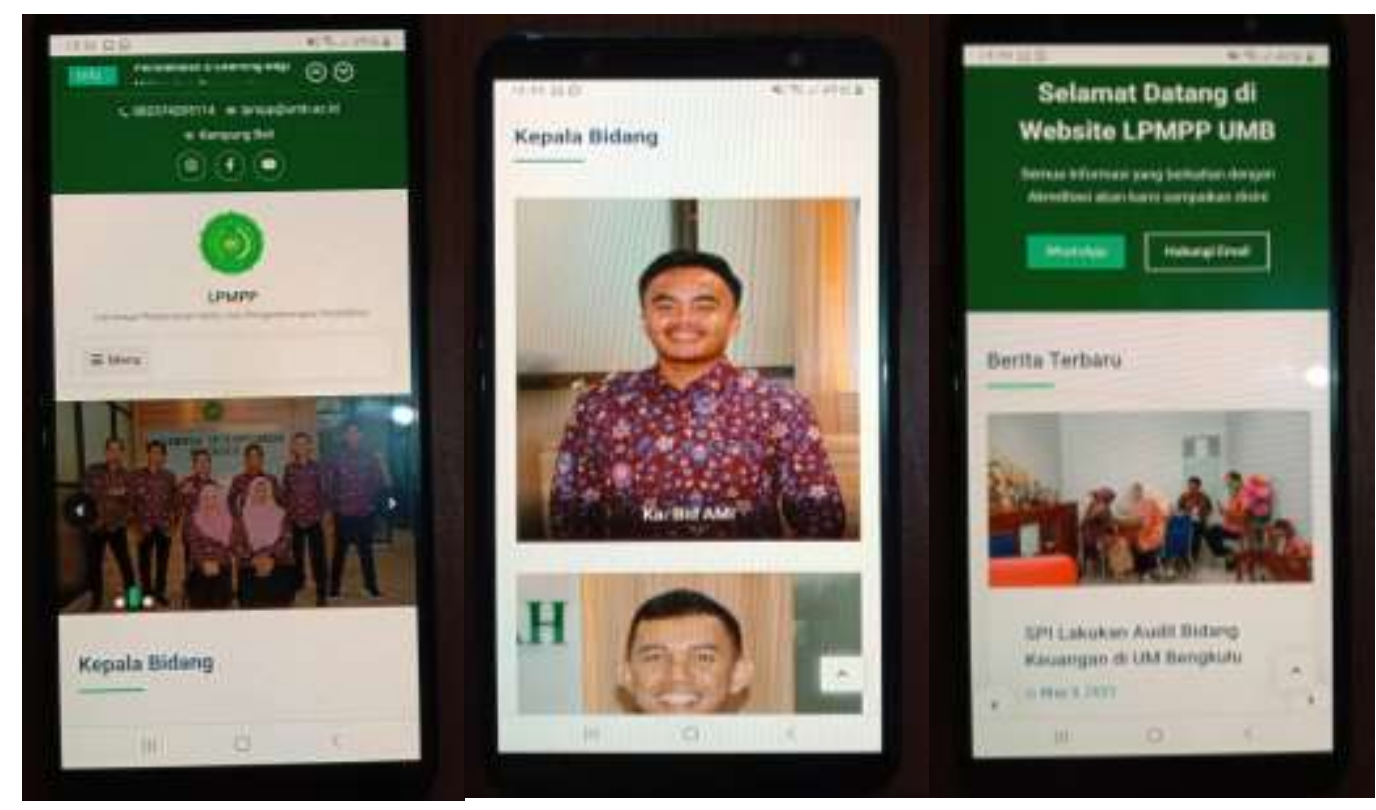

Gambar 6. Tampilan Website (akses HP android Samsung J8)

8. Evaluasi dan Pembuatan Laporan Hasil Penelitian

Evaluasi dan laporan hasil penelitian disusun berdasarkan serangkaian tahapan- tahapan analisis yang telah dilakukan. Laporan hasil penelitan ini akan diterbitkan kedalam jurnal ilmiah nasional terkrediatsi S4/S5.

\section{KESIMPULAN / RINGKASAN}

Template Web responsive dan dynamis pada website Lembaga Penjaminan Mutu dan Pengembangan Pendidikan (LPMPP) sudah berhasil diimplementasikan dengan baik menggunakan template web wordpress berbayar dengan tema education soul ditambah dengan customize dan install beberapa plugin sehingga website LPMPP mampu menghasilkan informasi berupa website responsive yang mampu menyediakan seluruh data up to date yang dibutuhkan oleh perguruan tinggi dan program studi. Sehingga efesiensi dan kepraktisan data dapat diakses malalui website yang akan telah dihasilkan 


\section{DAFTAR PUSTAKA}

Alatas, Husein. 2013. "Responsive Web Design Dengan PHP Dan Bootstrap." LokoMedia 1(3): 1-231.

Anugerah, Subur. 2013. "Pemodelan Responsive Web Menggunakan Foundation Framework Dalam Pengembangan Perangkat Lunak.” 2013(semnasIF): 23036.

Bettaliyah, Azza Abidatin. 2016. "Bahrul Ulum Berbasis Web Mobile Menggunakan.” Jurnal Teknika 8(2): 841-50.

Budiyono. 2016. "Rapid Web Application Development Menggunakan Template Dinamis." Semnasteknomedia Online 4(1): 6-7. https://ojs.amikom.ac.id/index.php/semnasteknomedia/article/view/1233.

Haryati, Siska, Aji Sudarsono, and Eko Suryana. 2015. "Implementasi Data Mining Untuk Memprediksi Masa Studi Mahasiswa Menggunakan Algoritma C4.5 (Studi Kasus: Universitas Dehasen Bengkulu).” Jurnal Media Infotama 11(2): 130-38.

Heny, Dwi Nugra. 2016. “Analisis User Interface Dan User Experience Pada Website Sekolah Tinggi Teknologi Adisutjipto Yogyakarta." Conference SENATIK STT Adisutjipto Yogyakarta 2: 183.

Irawan, Muhammad Dedi, and Selli Aprilla Simargolang. 2018. "Implementasi EArsip Pada Program Studi Teknik Informatika.” Jurnal Teknologi Informasi 2(1): 67 .

Nandari, Bhirawa Anoraga, and Sukadi. 2014. "Pembuatan Website Portal Berita Desa Jetis Lor.” Indonesian Journal on Networking and Security 3(3): 1-14. http://ijns.org/journal/index.php/ijns/article/view/272.

Suandi, Agus, Fata Nidaul Khasanah, and Endang Retnoningsih. 2017. "Pengujian Sistem Informasi E-Commerce Usaha Gudang Cokelat Menggunakan Uji Alpha Dan Beta." Information System for Educators and Professionals 2(1): 61-70. https://media.neliti.com/media/publications/234474-pengujiansistem-informasi-e-commerce-us-2bea597f.pdf. 
Wijaya, Ardi, and Gunawan. 2018. "Implementasi Algoritma Round Robin Pada Sistem Penjadwalan Mata Kuliah ( Studi Kasus: Universitas Muhammadiyah Bengkulu ).” Jurnal Informatika Upgris (JIU) 4(1): 64-71. http://journal.gris.ac.id/index.php/JIU/article/view/2336/1885up. 